\title{
Flush and run
}

A $s$ if there weren't enough justification to be wary about the possibility of acquiring an infection in a hospital, add yet another.

It seems that the flushing of lidless toilets, which are all too common in health care and other public facilities, or the flushing of a toilet with the lid up, in cases where the loo actually has a lid, results in the "aerosolization" of nasty little bugs like Clostridium difficile.

In situ testing of fecal suspensions of $C$. difficile detected the bug at heights of $25 \mathrm{~cm}$ above a toilet seat for as long 90 minutes after all the splashing and stirring of the environment that occurs when a toilet is flushed with its lid up (J Hosp Infect 2012;80[1]:1-5).

So gown, glove, hover, close (if the toilet has a lid), flush and run, because it appears that lids-down toilet flushing policies, or even the installation of lidded toilets for patients (in places where facilities don't currently have such apparent luxuries), aren't exactly high on the priority list of hospital infection- control measures.

"Probably the main answer to that is ... it's on a list of 100 things that need to be fixed," says Dr. Michael Gardam, medical director of infection prevention and control at the University Health Network in Toronto, Ontario. "I know people have talked about it. I have yet to see a single organization though that has implemented any kind of solution for this."

The UK study tested the dispersion of $C$. difficile, with toilet lid open and closed. When a toilet was flushed lid up, bacteria were found up to $25 \mathrm{~cm}$ above the seat. After 60 minutes, the number of bacteria decreased eightfold, and at 90 minutes, a further threefold. Lid down, none of the bacteria was found in the air above the seat after flushing.

When settle plates were positioned on the toilet seat, tank and floor around the toilet to measure the number of droplets ejected from the toilet after it was flushed with lid up, droplets were found on the left and right sides of the

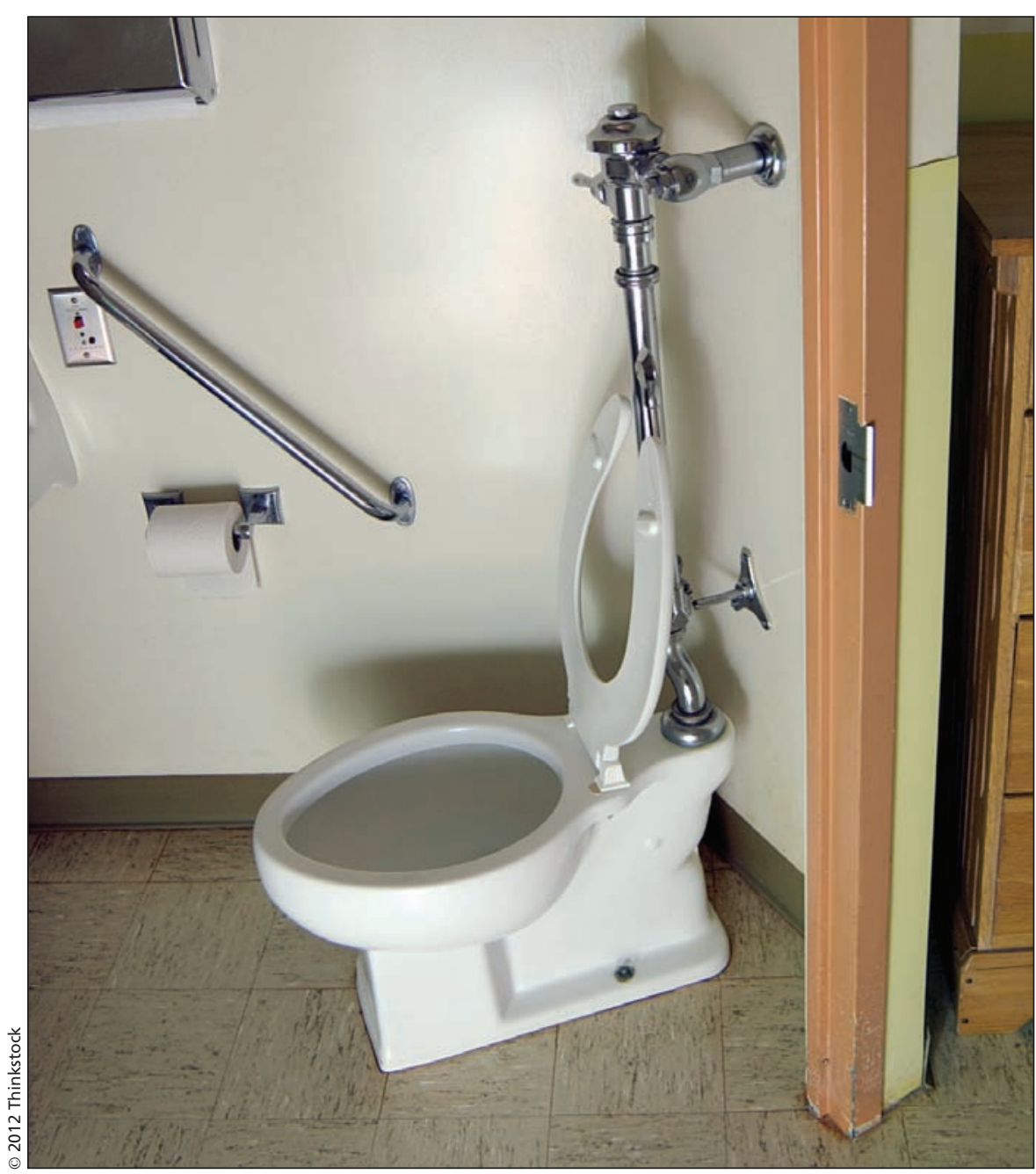

Hospitals often do not have lidded loos because it's believed they are too difficult for patients with mobility problems to utilize.

seat, tank and all but one of the three plates on the surrounding floor. But none were found when the toilet was flushed with the lid down.

Yet, simply installing lids may not be the answer, Gardam says. A lid that must be lifted for use and closed for flushing may cause problems for patients with mobility problems, he explains. That may necessitate more complex technological solutions to make it easier for such patients.

The issue seems to have "fallen off people's radar," Gardam adds. "There's been so much thought put into cleaning washrooms and what we're cleaning them with and that sort of thing that I think people may have perhaps lost sight of one simple thing you can do: develop a mechanism whereby you can actually seal the top of the toilet before you flush it."

But others pooh-pooh the notion of retrofitting toilets to ensure an automatic seal when they are flushed.

That would not guarantee fewer infections and may not be the best use of scarce hospital resources, says Dr. Doug Sider, medical director of communicable diseases and acting medical director of infection prevention and control for Public Health Ontario. 
"I'm not convinced that this will make a huge array of difference," Sider says. "This could be one of the mechanisms in which Clostridium difficile spores are spread within the hospital environment unbeknownst as much as it should be to us. That's a situation where yeah, it may be better to have lidded toilets, but how do you assure that after every use people put the lid down?"

Diligent cleaning of restrooms, proper hand hygiene and continued practice of other infection prevention and control measures are more effective measures, Sider argues. Even if a hospital were fully equipped with lidded toilets, the failure of one patient to wash his hands after touching the toilet would undermine the value of having a lidded loo, he says.

Whether or not it is C. difficilespecific "or whether it applies to a wider array of bacteria or viruses, that hospitals and other health care facilities are increasingly embedding practices and behaviours that whether you've got lidless toilets or lidded toilets, you're still reducing the likelihood of transmission from people using bathroom facilities," Sider adds.

The authors of the UK study speculated that asymptomatic carriers of $C$. difficile who use lidless toilets may be the cause of hospital outbreaks of the infection but because such patients are asymptomatic, isolation wasn't imposed.

"It really highlights one of the many infection control problems we face in hospitals," Gardam says. "This is not an isolated problem; there are many, many such problems. People really haven't, I think until relatively recently, put a lot of thought into what role the environment is playing in patient-to-patient transmission, and I think this kind of drives it home." Michael Monette, CMAJ

CMAJ 2012. DOI:10.1503/cmaj.109-4196 